\title{
Chomskyan Linguistics and the Scientific Methodology in Linguistic Study
}

\author{
Fuzhen Si \\ School of Foreign Languages, Beijing Language and Culture University \\ No 15, Xueyuan Road, Beijing 100083, China \\ Tel: 86-10-8238-6732, 86-999-896-2234Ｅ-mail: sifuzhen@blcu.edu.cn
}

The Project Sponsored by the Scientific Research Foundation for the Returned Overseas Chinese Scholars, State Education Ministry.

\begin{abstract}
This article is mainly concerned with Chomskyan linguistics, especially its methodology. The author of the paper argues against Shi Yuzhi(2005) and holds that although the relation between theoretical hypotheses and observations is, in some sense, like chickens and eggs and therefore to say that this paradigm is a top-down approach that is bottom-up one is too simple, theoretical hypothesis does function as directive force in scientific research and can be prerequisite to proper and effective experiments and observations. "Observations are meaningless unless we know what regularity they are supposed to illustrate." As for the stability of linguistics theory, the author thinks that linguistics, just like other sciences such as chemistry and physics, in order to prove specific ideas and hypothesis, scientists normally change their experimental programs frequently. What changed in Chomksyan linguistics are the experimental programs, the change from Government and Binding theory to the Minimalist Program as an example; what changed are technical details. And the hypothesis and main point of views never changed in general.
\end{abstract}

Keywords: Chomskyan linguistics, Scientific methodology, Top-down, Bottom-up

\section{Introduction}

Shi Yu-zhi(2005) argues against Chomskyan linguistics "by means of scientific methodology", in particular against the methodology of Chomskyan linguistics. He says the "formal method" of Chomskyan linguistics doesn't satisfy the requirements of the applications of scientific methods. He criticizes the "top-down" methodology of Chomskyan linguistics and says the general procedure of scientific study should be "bottom-up". He also gives veiled and rounded criticism about the frequent change of Chomskyan linguistics. Based on these, he concludes, "Chomskyan theory is not successful as a whole", and then introduces his theory of "compositional language faculty". In the discussion that follows, I review Shi Yu-zhi's arguments against Chomskyan linguistics and attempt to show that they not stand up to scrutiny. As readers may find, Shi misrepresents and misunderstands Chomskyan linguistics in many aspects. The theory behind these issues is too broad and is, aside from a brief discussion to the subject, beyond the boundaries of this paper. In what follows, therefore, I limited myself to only some of the main issues. In section 2, I discuss the main methodological issues that Shi raises. In section 3, I address my points on the frequent change of Chomskyan theoretical paradigm. And in section 4, I note that theoretical critiques and theoretical establishment should base on scientific theoretical criteria instead of simple affirmations or negations.

\section{General procedure of scientific study: top-down approach versus bottom-up approach}

Shi (2005) seems mainly concerned with questions of method. He devotes a full section (section 3) to arguing against the scientific methodology of Chomskyan linguistics. He deems normal process of scientific study begins from study of idiographic phenomenon and then develops a theoretical system by abstracting from the phenomenon step by step. But Chomskyan linguistics, in his view, established a system of abstract rules first, which is a result of analogy between language and mathematics and other things and bears no similarities to language, and then handle the real languages in a procrustean way by using such cut-and-dried formal rules. He thinks that such a hypothetico-deductive method or top-down method is totally wrong, and argues "in order to build up a palace of linguistics, one must follow the way of 
'bottom-up' to do groundwork." The evidences supporting his points are from history of science. Newton Apple and Mendel Peas are his examples. By saying Newton was enlightened by the fact of apple's falling to the ground so he found the classical mechanics, and Mendel established genetics based on his experience of peas planting, Shi tries to prove that the correct methodology of linguistic study should be bottom-up.

First thing I would like to address here is that scientific methodology in linguistic study is a big issue indeed that deserves discussion. However, it is more complicated than what Shi (2005) expectes. With regard to the so-called top-down approach and bottom-up approach, it is hard to say which one is more scientific from a technical perspective. For instance, in the field of computing, it is always the case that Natural Language Processing uses the top-down methodology, whereas robotics uses the bottom-up approach. Technically, both approaches have their advantages and their disadvantages. The top-down approach has the advantage of having all the necessary knowledge already present for the program to use, and thus is can perform relatively high-level tasks such as language processing. The bottom-up approach has the advantage of being able to model lower-level human functions, such as image recognition, motor control and learning capabilities. Obviously, Shi (2005) uses the terms of top-down and bottom-up in a different way and in his terminology, "top" refers to theories and hypothesis and "bottom" refers to observation and experiment. By using the term of "top-down" approach, he criticizes the over-attention to theoretical establishment of Chomskyan linguistics. Notice that critiques of Chomskyan linguistics for over-attention to theoretical works at the expense of data can be heard occasionally. As early as in 1960s, Bolinger (1960) criticized Chomskyan linguistics because of it. Robins (1973) remarked that Chomskyan linguistics represents a "theory-oriented" stage in history of linguistics, rather than a "data oriented" stage. Now Shi (2005) repeats a similar point in a Chinese version. Considering it is still representative, particularly in humanities, I plan to discuss this issue at first.

The following discussions will show that both Shi's points and his evidences constitute misrepresentations. Let us begin from considering his evidence of Newton Apple. Undoubtedly, the story of Newton and the falling apple are the best-known anecdote in the entire history of science. According to W.C.Dampier (1958), the observation and thoughts about universal gravity were guided by Galilean ideas about force. Galileo was the first to notice that the objects are "pulled" towards the center of the earth. But Newton showed this same force, i.e. gravity was responsible for the orbits of the planets in the solar system. Newton determines that gravity controls the motion of objects in the universe. According to a legend, Newton worked in Cambridge University and when the bubonic plague swept through Europe in 1665-66, the University shut down and all faculty and students were sent home. It was here in his garden at Woolsthorpe that the apocryphal story of an apple falling from a tree caused him to speculate the force required to cause this event might be the same force that holds the moon in place around the Earth. Researchers and instructors often take this legend as example for different purposes. Thing is that the story is often misused. By using the story of Newton Apple, Shi tries to prove that observations are more important than theoretical hypotheses and therefore should be prerequisite to theory establishment. Correspondingly, the "scientific procedure" should be going from phenomenal observation to theory abstraction, or in his words, from bottom to top. Obviously, Shi has magnified the significance of observations and experiments and has inverted the relation between theoretical paradigm and experiments. He ignored a fact that Newton's thought of universal gravity based on Galilean hypothesis about "force", instead of on pure observation without hypothesis. Lots of materials from history of science showed that theoretical hypotheses always function as a forerunner of observations. It is the same in the story of Newton Apple. We can imagine that without theoretical deliberation, Newton would not find anything, even if he observed the phenomena that apple falls from tree for hundreds of times. The same is true in genetics. Again, by saying "Genetics started from Mendel's experiences of pea-planting." Shi wants to prove that correct scientific method is to do observation in advance before theoretical works. Setting aside his points again and considering his evidence, it is another misunderstanding actually. The truth of the history of science tells us that the observational activity of pea planting was just a kind of experiment used to prove Mendel's theoretical hypothesis. Mendel's successful experiments of peas hybridization owed to his believe of the laws of segregation and independent assortment and his hypothesis of development of hybrids. And based on his thinking of development of hybrids, he grew many different strains of peas, and did lot of experiments by applying the methods of physics and mathematical methodology to a fundamental biological problem. As Magner (1994) said, it is virtually impossible to believe that such a prodigious amount of effort would have been undertaken without a well-conceived hypothesis and a precise experimental program." Notice that, Mendel's Law was a development of Naudin's idea concerning segregation in hybrids. Both Darwin and Mendel were interested in Naudin's idea, but Darwin did not think that Naudin's hypothesis concerning segregation in hybrids could explain reversion to distant ancestral traits. As a result, while Darwin was puzzling over Naudin's observations, Mendel was conducting a remarkably systematic experimental analysis of this phenomenon in an Augustinian monastery garden. It was the theory Mendel had previously formulated triggered him to design and achieve the famous experiments. It is tempting to imagine that if Mendel had no any idea about the development of hybrids, he would find nothing about the Mendel Law, even if he had rich of experience of peas breeding. In thinking all of these facts, we can conclude now that Shi has exaggerated the sudden enlightenment that allegedly occurred at the moment of observation and ignored the directive force of theoretical expectation and 
theoretical establishment and therefore his conclusion is problematic. As a matter of fact, the points exaggerating the significance of observations and experiments can be heard occasionally, even in the field of sciences. Kuhn (1996) called it as "excessively Baconian method": "Perhaps it is not apparent that a paradigm is prerequisite to the discovery of laws like these. We often hear that they are found by examining measurements undertaken for their own sake and without theoretical commitment. But history offers no support for so excessively Basonian a method.” History of science has showed us that good paradigm will not only suggest which experiments would be worth performing and which would not, but also predict what might happen. "In fact, so general and close is the relation between qualitative paradigm and quantitative law that, since Galileo, such laws have been correctly guessed with the aid of paradigm years before apparatus could be designed for their experimental determination." (Cf. Kuhn 1996)

Turn now to the methodology of linguistics. The same is true in the field of linguistics. Theoretical expectation has functioned as a directive force in many aspects of contemporary linguistics, particularly in Chomskyan linguistics. Lots of interesting phenomena and laws have been discovered in the light of Chomskyan paradigm. As Newmeyer (1996) said, "Generative grammarians have seen the tasks of description and explanation as wholly complementary. But no description is theory-neutral. The practice, therefore, has been to appeal to language-particular facts only in so far as they bear on a theoretical proposal; theoretical proposals have been judged successful in part to the extent to which they have in turn let to coverage of a wider variety of language-particular facts." Although the relation between theoretical hypotheses and observations is, in some sense, like chickens and eggs and therefore to say that this paradigm is a top-down approach that is bottom-up one is too simple. Theoretical hypothesis does function as directive force in scientific research and can be prerequisite to proper and effective experiments and observations. "Observations are meaningless unless we know what regularity they are supposed to illustrate." (Cf. Lees, 1965) Any point exaggerating the function of experiments and observations in scientific methodology is untenable.

\section{Stability and Changeability of theoretical paradigm}

Notice that to say that theoretical paradigm is prerequisite of observation doesn't mean that experiments and observations are not important. During and after a special paradigm is built up, there are lots of observations and experiments to be undertaken. Naturally, it is impossible that all facts and phenomena meet the theoretical expectation. Accordingly, some details of theoretical construction or techniques of experiments must change and develop in order to explain the facts in a more correct way. So, the frequent change of a theory implies its energy and vigor. Thinking about the change or the development of Chomskyan linguistics, we can say that the scientific observations and experiments, in some extent, have promoted the theoretical paradigm. However, not every one welcomes or could keep up with the change and development. As experts working in the field of Chomskyan linguistics, we are occasionally asked about the frequent change of Chomskyan linguistics. Quite a few of linguists criticize the paradigm because of its changeability. Similarly, at the beginning of his paper, Shi gives veiled and rounded criticism about it as another evidence against Chomskyan linguistics. With an eye to the representative trait, I plan to discuss it in brief.

Again, let us think about the issue of stability and changeability in a general and scientific perspective. As Kuhn(1996) said, we must recognize how limited in both scope and precision a paradigm can be at the time of its first appearance. The philosophical implicature is that every paradigm would change and develop in some respects, from an infantile stage into a mature stage, so that it can bring the facts and theoretical paradigm into closer and closer agreement. Therefore, whether for theory-oriented approach or data-oriented approach, the problem of consistency or agreement between theory and facts or theoretical hypothesis and experiments is always a big issue. History showed us that scientists have made great efforts for it. In the field of science, scientists have created lots of special apparatus and other things, such as Atwood's machine and Foucault's apparatus, to try to "bring nature and theory into closer and closer agreement." So "That attempt to demonstrate agreement is a second type of normal experimental work, and it is even more obviously dependent than the first upon a paradigm" (Cf. Kuhn, 1996). A natural and positive consequence of the efforts seeking the agreement and consistency between theory and facts might be the development and change of the theory. Considering all above-cited, one may not feel difficult to understand the motivation of the frequent change of Chomskyan linguistics.

In fact, Chomsky (2002) has mentioned his attitude about the change of the theory, "it is a young field, changes are taking place fast, there are lots of unexplained things. I am sure there are new perspectives that we haven't thought of yet. I wouldn't expect, or even hope for, stability." It is a scientific attitude, I think. The reason is that "if there's stability, it means we are not going to get very far, because, in the stage where we are now, there are just too many mysteries. So if the field remains stable, that means there are going to remain mysteries." (Cf. Chomsky 2002)

Having discussed the motivation of the changeability of Chomskyan paradigm, a natural question ask here is that, are there something stable in Chomskyan linguistics? The answer is YES. Although many things changed and developed, there are some things stable in the paradigm. Macroscopically, the philosophical thinking on the nature of language and mind never changed, the efforts seeking the answer of Plato's problem never changed, the main points of view on the Universal Grammar and the hypothesis of innateness never changed, and the efforts to reduce the variety and 
complexity of grammar never changed. Microcosmically, the general methodology and many important principles remain stable. In my understanding, in the field of linguistics, just like other sciences such as chemistry and physics, in order to prove specific ideas and hypothesis, scientists normally change their experimental programs frequently. What changed in Chomksyan linguistics are the experimental programs, the change from Government and Binding theory to the Minimalist Program as an example; what changed are technical details. And the hypothesis and main point of views never changed in general. As Lu Jian-ming (2004) said, "From a surface, it seems that Chomsky's theory changes every year which give some people an misunderstanding that his theory could not be amenable to time. As a matter of fact, his hypothesis and his theoretical aim never changed."

The conclusion is that, we need to understand the stability and changeability of a theoretical paradigm dialectically. What I want to stress here is that Change means theoretical energy in some resects and it is a normal way to do scientific work. Any one boasting that his theoretical system is unchangeable and can be used to get something done once and forever is anti-scientific and therefore unbelievable.

\section{How to criticize a theory and how to build up a theory?}

Last, I would like to give a very brief remark about the way in which Shi criticizes Chomskyan linguistics. In my opinion, a critique to a theory should base on proper criteria of criticizing, by argumentation, demonstration and reasoning. Chomsky (1965) developed criteria of "observational adequacy, descriptive adequacy and explanatory adequacy". Now researchers still use it in different theoretical levels. Going through whole paper of Shi (2005), we found that in spite of his title is "The philosophical foundations and defects of Chomskyan linguistics and the introduction to Compositional Language Faculty”, he rarely mentions the works that reflect Chomksyan philosophy. Instead, the paper is full of conclusive affirmations and negations without demonstration, reasoning. Return to his theory of "Compositional Language Faculty", on the other hand, except for a list of general psychological knowledge that every people know, he doesn't provide us any scientific reasoning, demonstration and argumentation. Based on all above-illustrated, one can easily find that Shi's argumentations are lack of powerful theoretical basis and therefore his conclusion about "Chomskyan theory is not successful as a whole" is weak and untenable. And his assumption of "Compositional Language Faculty" is far from mature.

\section{References}

Bateman, D. R. \& F. Zidonis. (1964). The Effect of Knowledge of Generative Grammar upon the Growth of Language Complexity. ERIC ED 001241.

Bolinger, Dwright. (1960). Linguistic Science and Linguistic Engineering. Word 16: 374-91.

Chomsk, N. (1965). Aspects of the Theory of Syntax. Cambridge, Mass: MIT Press.

Chomsky, N. (2000). New Horizons in the Study of Language and Mind. Cambridge: Cambridge University Press.

Chomsky, N. (1957). Syntactic Structures. The Hague: Mouton.

Chomsky, N. (1991). Linguistics and Cognitive Sciences: Problems and Mysteries. In Asa Kasher (ed.) The Chomskyan Turn: Generative Linguistics, Philosophy, Mathematics, and Psychology. Oxford: Blackwell,26-55.

Chomsky, N. (1995). The Minimalist Program. Cambridge, Mass: MIT Press.

Chomsky, N. (2002). On Nature and Language. England, Cambridge: Cambridge University Press.

Chomsky, N. (2004). Generative Enterprise Revisited: Discussion with Riny Huybregts, Henk Van Riemsdijk, Naoki Fukui, and Mihoko Zushi, With a New Forward by Noam Chomsky. Berlin, New York: Mouton De Gruyter.

Culicover, P.W. (1982). Syntax. New York, London: Academic Press.

Dampier, W.C. (1958). A History of Science and Its Relative with Philosophy and Religion. Revised and Enlarged. Cambridge: Cambridge University Press.

Gueron, J. and L. Haegeman, (1998). English Grammar: A Generative Perspective. (Blackwell Textbooks in Linguistics). Oxford: Blackwell.

Kuhn, T.S. (1996). The Structure of Scientific Revolutions, The University of Chicago Press.

Lees, R. (1960) The Grammar of English Nominalizations. The Hague: Mouton.

Lu Jian-ming. (2004). A Preface of Yuan Yu-lin (2004)'s A Cognitive Perspective of Chinese Grammar. in Beijing: The Commercial Publishing House.

Magner, L. N. (1994). A History of the Life Sciences.Parcel Dekker.

Newmeyer, F. J. (1980). Linguistics Theory in America: The First Quarter-Century of Transformational Generative Grammar. New York: Academic Press.

Newmeyer, F. J. (1996). Generative Linguistics: A Historical Perspective. London and New York: Routledge. 
Radford, A. (1997). Syntactic Theory and the Structure of English: A minimalist Approach. Cambridge: Cambridge University Press.

Robins, Robert H. (1973). Theoretical-orientation Versus Data-orientation: A Recurrent Theme in Linguistics. Historiographia Linguistica 1, 11-26.

Roger, H. (2000). Second Language Syntax: A Generative Introduction. Oxford: Blackwell.

Shi, Yu-zhi. (2005). The Philosophical Foundations and Defects of Chomskyan Linguistics and the Introduction to Compositional Language Faculty. Journal of Foreign Languages. No.157.Volume 3.

Smith, N. (2000). Foreword of Chomsky's New Horizons in the Study of Language and Mind. Cambridge: Cambridge University Press. 